\title{
ENSINO DE GEOGRAFIA FÍSICA ATRAVÉS DO TRABALHO DE CAMPO: UM RELATO SOBRE A LAGOA DO AÇU, REGIÃO NORTE DO ESTADO DO RIO DE JANEIRO
}

\author{
Adriana Cruz Ferreira $^{(\mathrm{a})}$, Ana Freitas de Carvalho $^{(\mathrm{b})}$, Thiago Vieira de Carvalho $^{(\mathrm{c})}$, Vinicius \\ Santos Lima ${ }^{(\mathrm{d})}$
}

\begin{abstract}
(a)Licenciando em Geografia pela Faculdade de Filosofia, Ciências e Letras de Macaé, drikas1969@gmail.com (b) Licenciando em Geografia pela Faculdade de Filosofia, Ciências e Letras de Macaé, anafreitask @ gmail.com ${ }^{(c)}$ Licenciando em Geografia pela Faculdade de Filosofia, Ciências e Letras de Macaé, tvieira.carvalho@gmail.com (d)Professor Adjunto da Licenciatura em Geografia da Faculdade de Filosofia, Ciências e Letras de Macaé, vinicius_ahriman@hotmail.com
\end{abstract}

\section{Eixo: GEOGRAFIA FÍSICA: CURRÍCULO, FORMAÇÃO E PRÁTICAS DE ENSINO}

\begin{abstract}
Resumo
Neste trabalho objetivou-se realizar um relato de experiência de uma atividade de campo realizada na lagoa do Açu, município de Campos dos Goytacazes, Norte do estado do Rio de Janeiro, como requisito parcial da disciplina Geologia Geral do curso de licenciatura em Geografia da Faculdade de Filosofia, Ciências e Letras de Macaé. A lagoa do Açu trata-se de um ambiente costeiro, onde há ocorrência de manguezais e restingas, bem como do Parque Estadual da Lagoa do Açu, criado como medida compensatória à implementação do Complexo Industrial e Portuário do Açu. Assume-se que o trabalho de campo é uma ferramenta de ensino fundamental na construção do saber, não podendo ser menosprezado, tendo em vista que no campo o aluno visualiza o que foi proposto em teoria, aproxima-se da realidade possibilitando a observação da paisagem, tornando possível, aprofundar os conteúdos desenvolvidos em sala de aula e levantar novas possibilidades de análises.
\end{abstract}

Palavras-Chave: Mudanças na paisagem; hidrogeografia; rio Paraíba do Sul.

\section{INTRODUÇÃ̃O}

O trabalho de campo surge no ensino como complementação e visualização da teoria aplicada em sala de aula. Dessa forma esse instrumento comprova que todos os conceitos expostos em sala de forma replicada, na verdade constitui uma grande rede de conhecimentos e informações que se inter-relacionam, de maneira complementar ou desconstroem algum dado anterior (CIRINO et al., 2009).

De acordo com Cirino et al. (op. cit.), esse trabalho utiliza o empirismo para obter resultados, a partir de uma observação consistente e antecedida pela teoria, assim poderemos perceber a grande contribuição para a formação de uma consciência resultante da relação de interdependência, entre o olhar e entender e/ou compreender o espaço, que é o foco da disciplina de Geografia.

Para tanto, assumiu-se como objeto do trabalho de campo a lagoa do Açu. A área de estudo está localizada em uma área de planície costeira da Região Norte Fluminense. Essa lagoa faz divisa com dois municípios 
da região: Campos dos Goytacazes e São João da Barra. Ela possui, aproximadamente, $13 \mathrm{Km}$ de extensão e um canal de 5 a $10 \mathrm{~m}$ de largura. Sua profundidade máxima varia de 2 a $3 \mathrm{~m}$ onde antes se encontrava o antigo leito do rio do Açu do qual se originou este ecossistema (MARQUES, 2002). Atualmente, a Lagoa do Açu é classificada como uma lagoa de restinga, separada do mar por uma estreita faixa de areia denominada barra (BIDEGAIN et al., 2002). Neste cenário composto por restinga e mangue, podem ser encontradas espécies.

Para Freesz et al. (1997), as lagoas costeiras são importantes componentes da paisagem na região Norte Fluminense. Constituem-se em ricos ambientes nos quais ocorrem complexos processos ecológicos, funcionando também como locais de reprodução e proteção de espécies aquáticas e semiaquáticas; dentre as quais se encontram diversas espécies de aves.

Devido a sua importância e com o intuito de contribuir para a preservação deste ambiente, foi criado o Parque Estadual da Lagoa do Açu, através do Decreto n 43.522 de 20 de março de 2012, o Parque Estadual da Lagoa do Açu (PELAG) possui uma área de 8.251,45 hectares, abrangendo parte dos municípios de Campos dos Goytacazes e São João da Barra, também na região do litoral Norte do estado do Rio de Janeiro. É uma unidade de conservação de proteção integral. Ele assegura a preservação de remanescentes de vegetação nativa de mata atlântica como restinga e mangue (INEA, 2012).

Distintos pesquisadores vêm empreendendo esforços para melhor pensar os ambientes lênticos da planície costeira do rio Paraíba do Sul. Dentre os mais recentes trabalhos, destaca-se um grupo de intelectuais composto por laboratórios do Instituto Federal Fluminense, Universidade Federal do Espírito Santo e Universidade Federal Fluminense (ALVES et al. 2016; LIMA e COELHO, 2016).

Lagoas são objeto de estudo de diferentes campos do saber, a exemplo da limnologia, oceanografia e da geologia. Segundo Lima et. al. (2014), a ciência geográfica não tem dado a devida atenção aos ambientes lacustres, que em alguns casos, é fonte de abastecimento para cidades. De acordo com os autores, lagoas são "copos", ou condutos geográfico-geomorfológicos para onde vazam águas de uma bacia hidrográfica, mas que não devem ser pensadas somente em função do alcance espacial de seu espelho e profundidade da coluna d'água em cheias de pequeno intervalo de retorno, mas sim das cheias excepcionais. Assim, os gestores do território melhor poderão gerir esses espaços.

Por se tratar de uma região pantanosa, a planície costeira do rio Paraíba do Sul é objeto de pesquisa, extensão e ensino. De acordo com Lima e Coelho (2016) a lagoa do Açu é um antigo rio, para onde corriam as águas da margem direita do rio Paraíba do Sul, concentradas, primeiro na lagoa Feia e, desta para o extinto rio. Toda a paisagem hídrica da região sofreu intensa transformação antropogênica, com 
drenagem de lagoas através da construção de uma complexa malha de canais artificiais, o que torna a lagoa do Açu uma "sala de aula aberta", onde interagem aspectos físicos e sociais.

Neste sentido, traçou-se como objetivo central deste trabalho, relatar a experiência de uma aula de campo com estudantes do $2^{\circ}$ período da Faculdade de Filosofia, Ciências e Letras de Macaé realizada no dia 05/11/2016 na lagoa do Açu, atentando para as alterações na paisagem e proporcionando maior integração entre o educando e o educador. Ressalta-se que o trabalho de campo compôs parte integrante da disciplina Geologia Geral do curso de licenciatura em Geografia.

\section{METODOLOGIA}

O trabalho de campo se trata de construção contínua de um saber científico que também pode fazer parte da vida do discente. Nesse sentido, alguns critérios são levados em consideração ao pensar a aula de campo como mediadora do conhecimento em Geografia Física (SILVA et al., 2010; GARÇÃO E CAMPOS, 2012), quais sejam:

a) Escolha do local, considerando a acessibilidade (local, transporte, alimentação e hospedagem;

b) Elaboração do projeto de aula de campo que esclareça bem os objetivos e as metodologias a serem utilizadas;

c) Revisão bibliográfica;

d) Preparação de um roteiro detalhado das atividades de campo;

e) Orientação a respeito da análise integrada da paisagem;

f) Estabelecimento de critérios disciplinares, como horários, normas de conduta, cuidados com acidente e saúde.

Neste sentido, o trabalho de campo ocorreu no dia 05 de novembro de 2016, com início às 07:30h e término às 20:30h. O grupo saiu de frente da FAFIMA (Faculdade de Ciências e Letras de Macaé) com licenciandos do $2^{\circ}$ período do curso de Licenciatura em Geografia da FAFIMA a caminho da cidade de Campos dos Goytacazes. Ao chegar ao destino o grupo encontrou-se com o professor o Prof ${ }^{\mathrm{o}}$. M.Sc. Vinicius Santos Lima, coordenador da disciplina e os professores convidados José Maria Ribeiro Miro (UFF-Campos) e Raquel da Silva Paes (UFF - Campos).

Foram realizadas as devidas apresentações e a exposição de um mapa da região, com ênfase aos locais onde haveria os estudos, para os alunos poderem se localizar e ambientar com o espaço estudado. Os pontos de estudo foram: Canal Campos-Macaé, foz do rio Paraíba do Sul, Lagoa do Açu e Lagoa Salgada. 


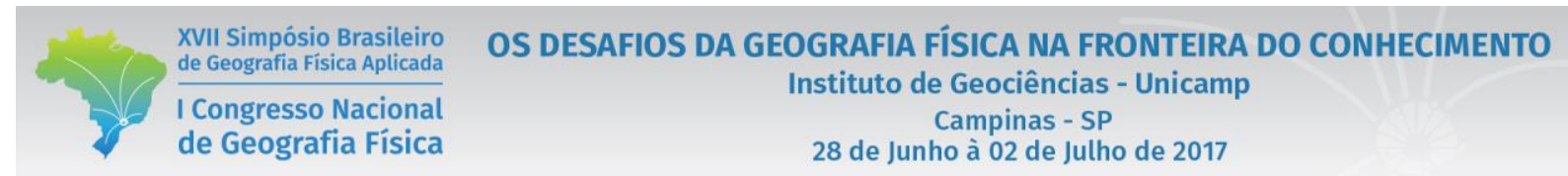

Dentre os instrumentos técnicos utilizados encontram-se mapas temáticos, como geológicos, hidrogeográficos e geomorfológicos, além de uma bússola para noções básicas de orientação cartográfica.

\section{RESULTADOS E DISCUSSÃO}

A Lagoa do Açu (Figura 1) está localizada na planície costeira do rio Paraíba do Sul, fazendo divisa com dois municípios: Campos dos Goytacazes e São João da Barra, ambos na região Norte do estado do Rio de Janeiro.

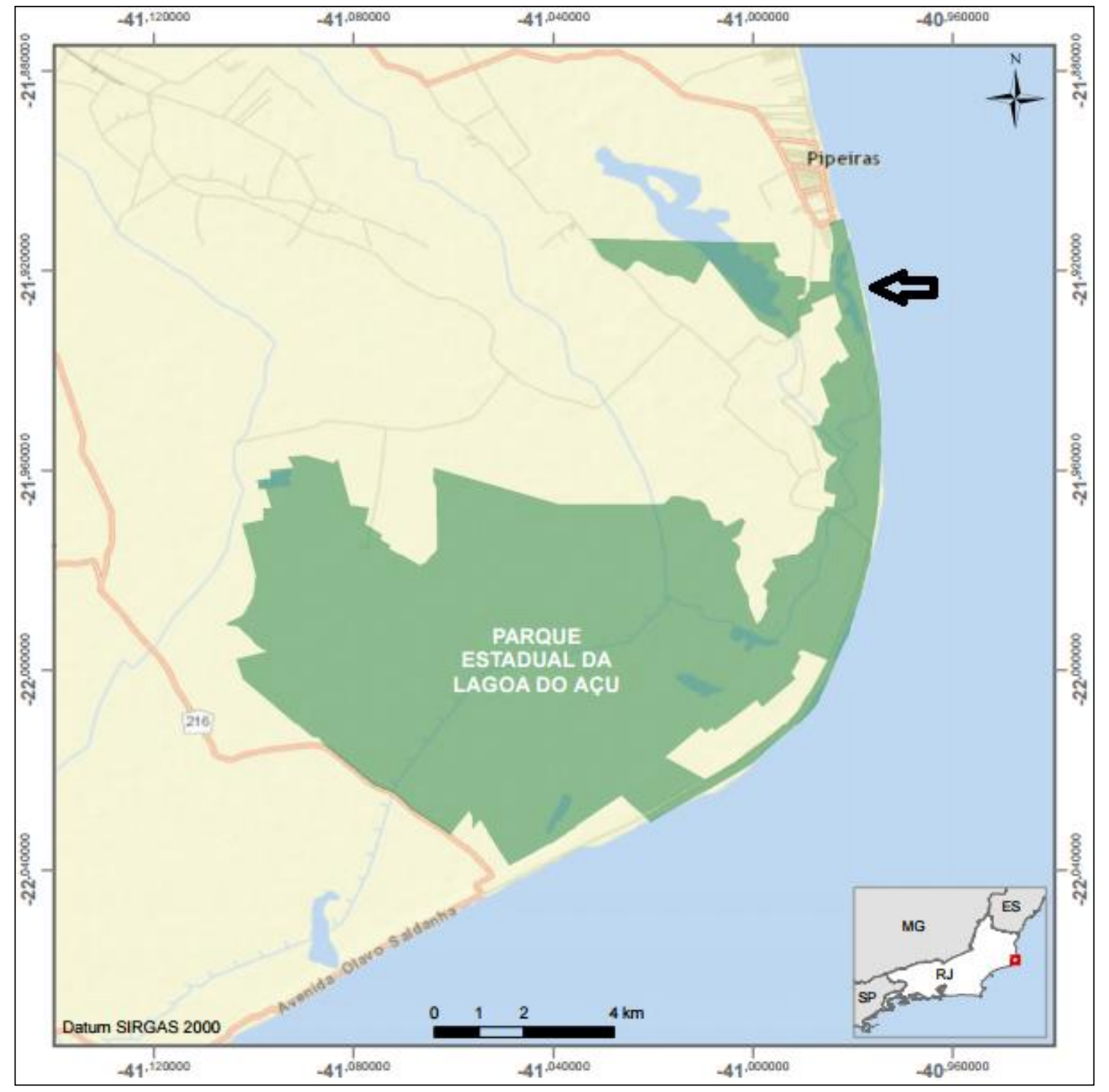

Figura 1 - localização do Parque Estadual da Lagoa do Açu, com destaque à lagoa homônima. Fonte: Instituto Estadual do Ambiente - INEA. 
Amador (1986), Trindade (1996), Esteves (1998) e Suguio (2003) propuseram tipologias de lagoas que ocorrem na área de estudo baseados nos processos formadores, nas forças atuantes e nas características limnológicas destas entidades geomorfológicas. Contudo, estes trabalhos apresentam resultados em escalas de pouco detalhe, não havendo estudos geomorfológicos expressivos que as explique sob a perspectiva da análise da paisagem.

As lagoas possuem expressiva ocorrência espacial no Baixo Paraíba do Sul, sobretudo, em sua planície deltaica. Elas apresentam importância econômica, enquanto fonte de renda para muitas famílias que vivem da pesca, como as que habitam a vila de pescadores de Ponta Grossa dos Fidalgos; ecológica, enquanto complexos ecossistemas que estão interligados superficial e subsuperficialmente e; social, sendo destino de turistas ou autóctones para a prática do lazer e da educação ambiental (LIMA, 2014).

A mais recente proposta de tipologia de lagoas na região, no campo da geografia física, foi realizada por Alves et al. (2013), na qual os autores sugerem 5 (cinco) classes, a saber: 1) Laguna de rios barrados formada através da obstrução da foz de rios no litoral; 2) Lagoa deltaica - formada por depressões nos depósitos flúvio-marinhos; 3) Lagoa de meandro abandonado - formada pelo abandono de trechos de rios; 4) Lagoa reliquiar - formada entre cordões de restinga; 5) Lagoa de tabuleiro - formada nos vales do Grupo Barreiras.

A lagoa do Açu enquadra-se em "Laguna de rios barrados". Sua formação se dá quando sedimentos marinhos são depositados na desembocadura de rios, isolando seus estuários, formando barras arenosas que impedem a ligação direta com o oceano (Figura 2). Estas barras podem ser removidas naturalmente em momentos de grande precipitação nas cabeceiras dos rios, coincidindo com os fenômenos de ressacas marinhas. Outra forma de abertura de barra é aquela realizada por comunidades tradicionais de pescadores com a finalidade de promover a comunicação da lagoa com o mar, permitindo a entrada de alevinos, para garantir seu modo de vida. Atualmente, o Estado também promove a abertura das barras para fins de saneamento de áreas ocupadas nas suas faixas marginais (ALVES et al., 2013). 
XVII Simpósio Brasileiro de Geografia Fisica Aplicada

I Congresso Nacional de Geografia Física
OS DESAFIOS DA GEOGRAFIA FÍSICA NA FRONTEIRA DO CONHECIMENTO

Instituto de Geociências - Unicamp

Campinas - SP

28 de Junho à 02 de Julho de 2017

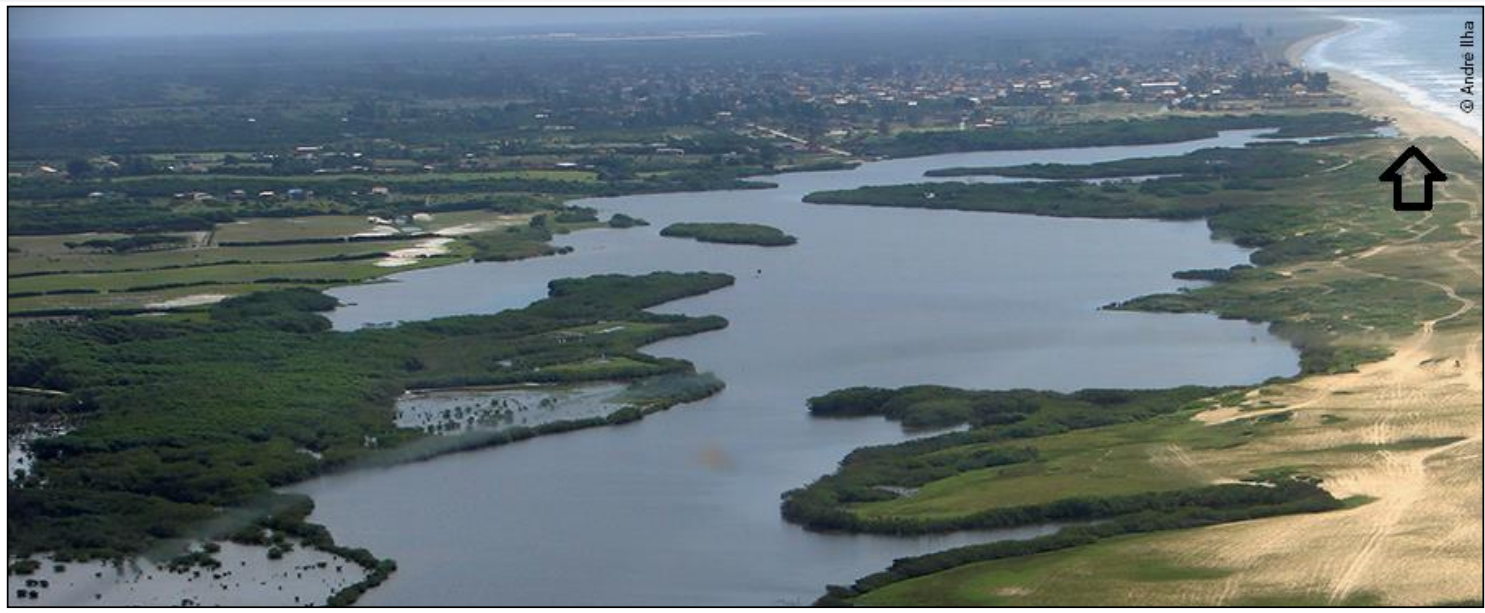

Figura 2 - Lagoa do Açu com destaque à barra. Fonte: Instituto Estadual do Ambiente.

No trabalho de campo foi discutido que, a despeito da lagoa do Açu hoje encontrar-se sob a morfologia de um ambiente lêntico, em tempos passados sua dinâmica era lótica (Figura 3). Tratava-se de um rio para onde vazavam as águas da lagoa Feia. A lagoa Feia é o grande "bolsão" de destino das águas da margem direita do rio Paraíba do Sul em seu baixo curso, alimentada por águas que vertem da Serra do Mar através dos rios Imbé-Ururaí e Macabu, além de uma complexa malha de canais artificiais que totalizam mais de $1.200 \mathrm{~km}$, construídos pelo extinto Departamento Nacional de Obras e Saneamento - DNOS. 

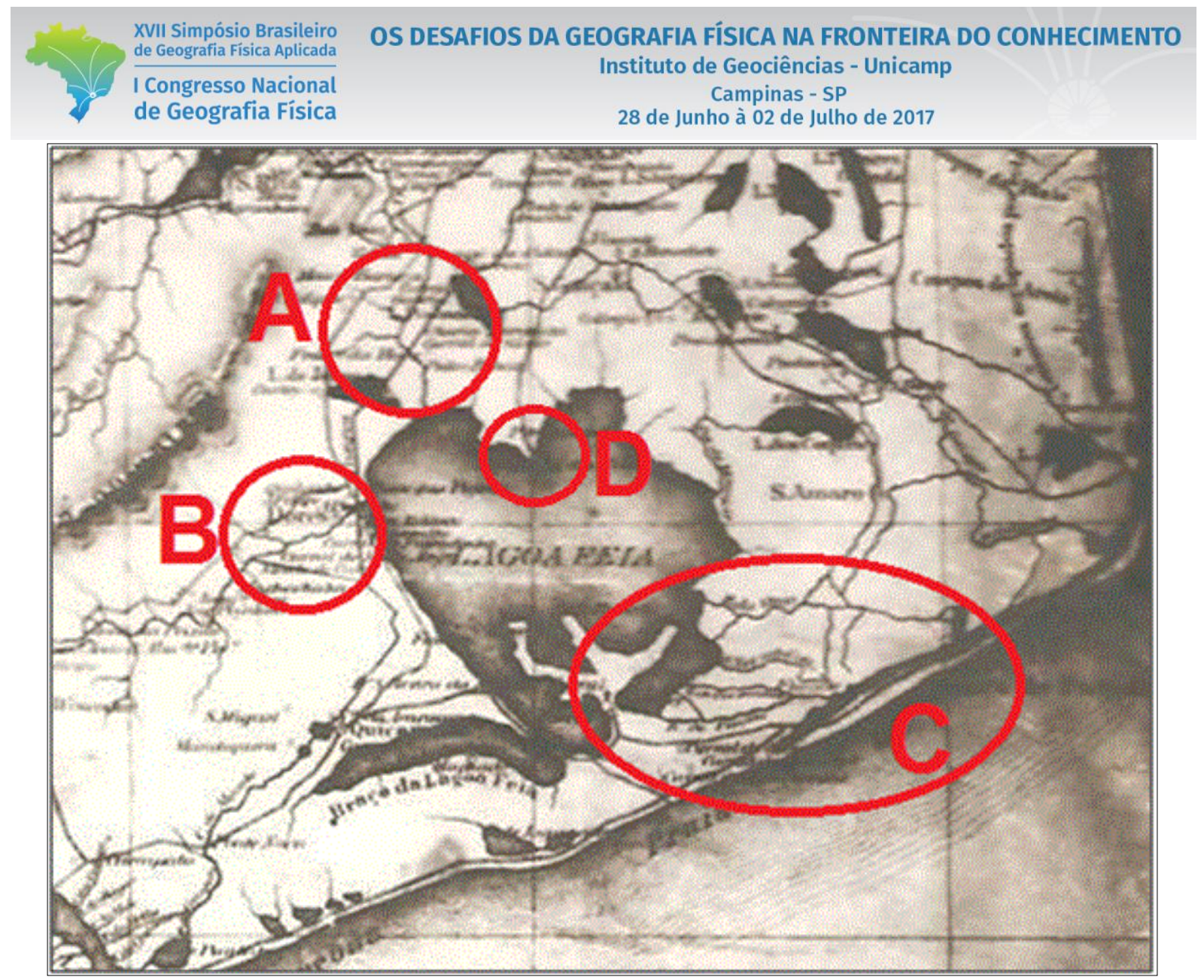

Figura 3: Carta Corográfica e Administrativa da Província do Rio de Janeiro e do Município Neutro. A: trecho do rio Ururaí ainda não retilinizado; B: trecho do rio Macabu ainda não retilinizado; C: rede natural dos rios da Onça, Novo, do Ingá, do Barro Vermelho e do Furado que ligavam a lagoa Feia ao extinto rio Iguaçu e este ao oceano Atlântico; D: Ponta Grossa dos Fidalgos. Fonte: Adaptado de Soffiati Netto (2005).

O projeto do DNOS se pautava na "ideologia progressista" de superação do atraso em que se encontrava a região, ou seja, sua revitalização. O objetivo das Comissões de saneamento estava ligado ao aproveitamento das áreas que seriam saneadas, para uso de atividades econômicas, como a agricultura, transporte de mercadorias e também, como serviço de higiene pública (LIMA et al., 2014).

Foi debatido em campo como os órgãos governamentais criam espaços, assim como entidades privadas. $\mathrm{O}$ uso da terra e das águas na lagoa do Açu e suas áreas adjacentes passou por muitas mudanças antropogênicas, alterando diretamente a configuração da paisagem. Hoje, a lagoa (Figura 4) está inserida em uma unidade de conservação integral. Trata-se do Parque Estadual da Lagoa do Açu, criado em 20 de março de 2012 através do Decreto n 43.522, com área de 8.251,45 hectares (ver Figura 1), como medida compensatória à construção do Complexo Industrial e Portuário do Açu. 


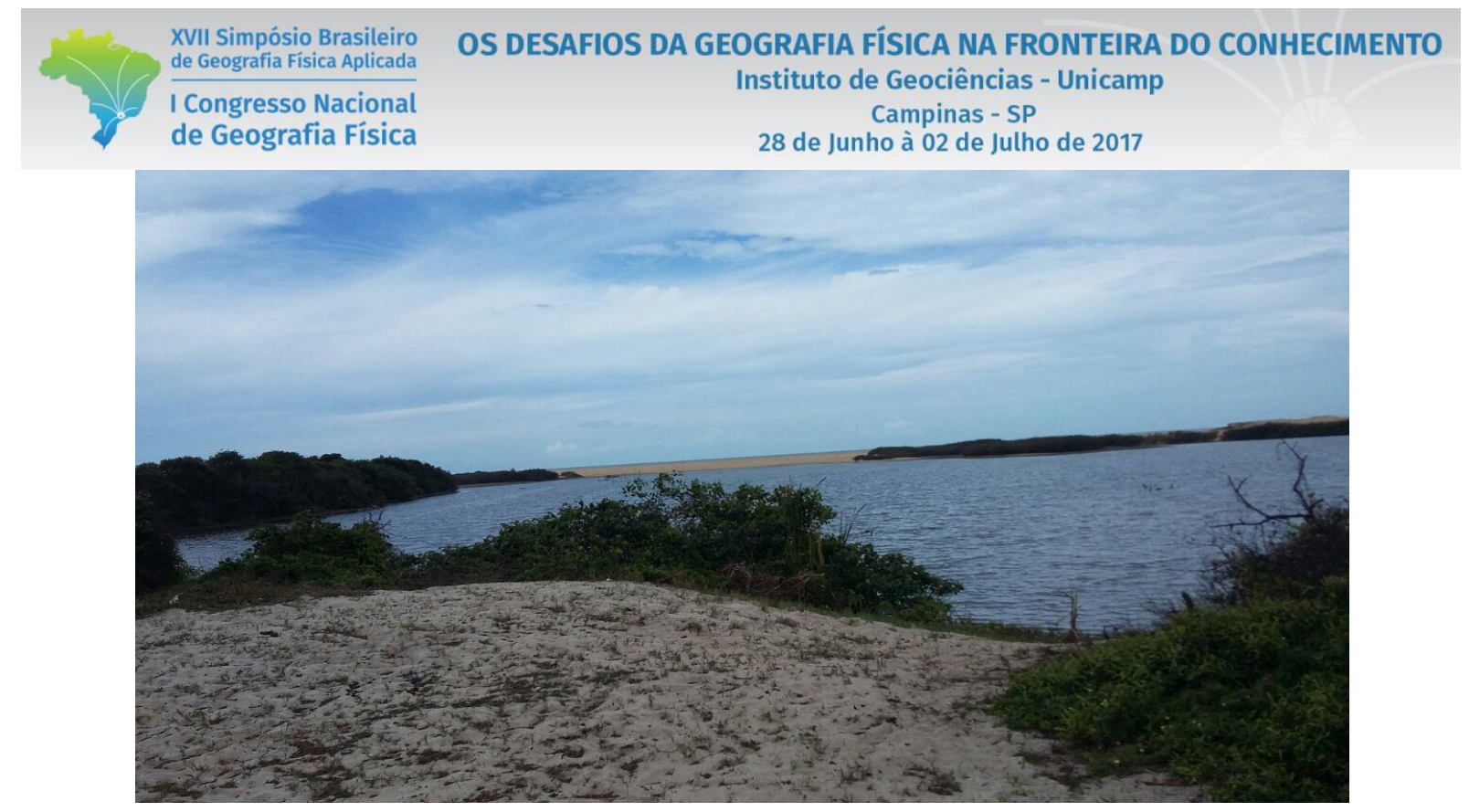

Figura 4: Observação da lagoa do Açu in loco. Fonte: Dos autores - 05/11/2016.

Por fim, observou-se que, em função de sua localização geográfica costeira, a lagoa conta com distintos ecossistemas, como manguezal e restinga, o que torna o solo bastante arenoso, falicitando processos de lixiviação, além de uma expressiva presença de serrapilheira (Figura 5). 


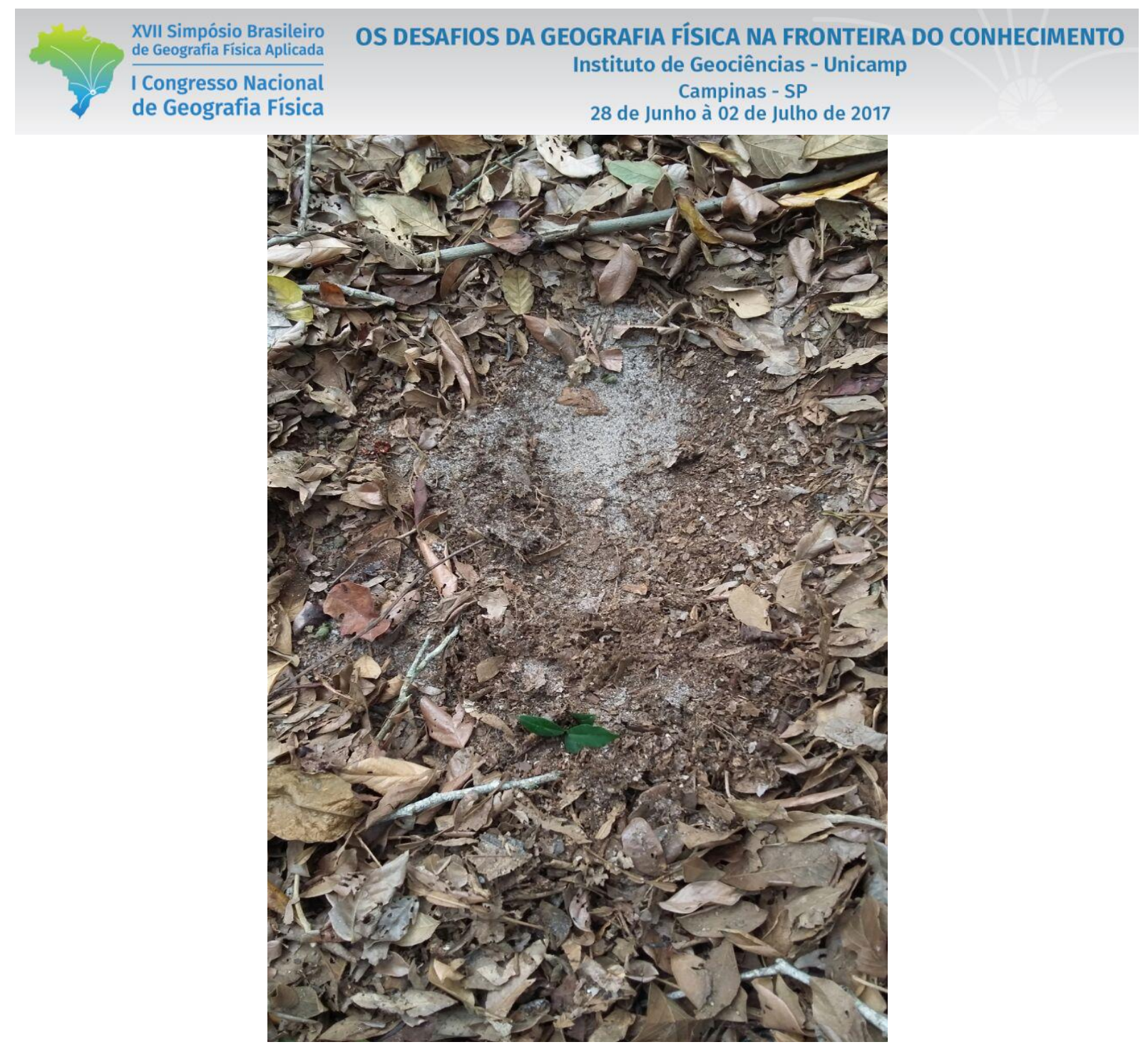

Figura 5 - Serrapilheira às margens da Lagoa do Açu. Fonte: Dos autores - 05/11/2016.

\section{CONCLUSÃO}

Conclui-se que, por mais que se tenha a teoria, sempre haverá o que acrescentar quando estamos em prática de campo. Este trabalho resultou em uma prazerosa forma de conceituar a paisagem, a partir de conteúdos anteriormente discutidos na disciplina de Geologia Geral em sala de aula. Ressalta-se a importância da atividade de campo como um ferramental imprescindível na construção do conhecimento junto aos discentes, estreitando a relação teoria-prática e potencializando o processo de ensinoaprendizagem.

\section{BIBLIOGRAFIA}


ALVES, Leidiana Alonso; LIMA, Vinícius Santos; MIRO, José Maria Ribeiro COELHO, André Luiz Nascentes. Classificação geomorfológica das lagoas da Região Hidrográfica do Baixo Paraíba do Sul - RJ. In: Anais XV Simpósio Brasileiro de Geografia Física Aplicada. Vitória, ES, 2013.

ALVES, L. A.; REIS, V. S. ; MIRO, J. M. R. . Conservação dos recursos hídricos: uma análise dos aspectos geológicos e geomorfológicos do Sistema Campelo. In: Anais XVIII Encontro Nacional de Geógrafos, 2016, Maranhão/MA. Anais XVIII ENG, 2016.

AMADOR, E. da S. Lagunas fluminenses: classificação com base na origem, idade e processos da evolução. Anais do $1^{\circ}$ Seminário sobre conservação de recursos pesqueiros. SUDEPE - RJ, 1986. p. 11 e 12.

BIDEGAIN, P.; BIZERRIL, C.; SOFFIATI, A., 2002. Lagoas do Norte Fluminense, Perfil Ambiental. SEMADS, Rio de Janeiro, 148p.

CIRINO, Bruna; DIAS, Rafael; FREITAS, Márcia; BRASIL, Filipi. A importância dos trabalhos de campo nas aulas sobre meio ambiente para turmas de ensino fundamental. In: Anais $10^{\circ}$ Encontro nacional de prática de ensino em geografia. Porto Alegre/RS, 2009.

ESTEVES, F. A. Fundamentos de Limnologia. Rio de Janeiro: Interciência, 1998. 602 p.

FREESZ, Nélia Paula; NOVELLI, Ronaldo; CORDEIRO JUNIOR, Luis Sérgio de Araújo. DINÂMICA DA AVIFAUNA DA LAGOA DO AÇU, NORTE FLUMINENSE, RJ. In: SICK, H. Ornitologia Brasileira. 2 ed. Rio de Janeiro; Editora Nova Fronteira, 1997.

GARÇÃO, Lucimar Marques da Costa; CAMPOS, Alfredo Borges de. Trabalho de campo no ensino de Geografia Física: um relato de experiência no Parque Estadual do Jalapão do Tocantins. In: Temporis (ação), v.11, n. 1, p. 115- 130, jan./dez. 2012.

INSTITUTO ESTADUAL DO AMBIENTE - INEA, 2012. Disponível em: < http://www.inea.rj.gov.br/Portal/Agendas/BIODIVERSIDADEEAREASPROTEGIDAS/UnidadesdeConservacao/IN EA_008601>. Acesso em: 22/12/2016.

LIMA, Vinícius Santos. Variação Espaço-Temporal do Espelho D'água da Lagoa Feia, RJ. Vitória/ES: UFES. Universidade Federal do Espírito Santo (Dissertação de Mestrado), 2014.

LIMA, Vinícius Santos; COELHO, André Luiz Nascentes; CUNHA, Sandra Baptista da. RECONSTITUIÇÃO AMBIENTAL DA LAGOA FEIA/RJ. In: Anais VI Congreso Iberoamericano de Estudios Territoriales y Ambientales. São Paulo/SP, 2014.

LIMA, Vinícius Santos; COELHO, André Luiz Nascentes. Impactos Antrópicos e Mudanças na Paisagem: Um Estudo Sobre a Lagoa Feia/Brasil. 1. ed. Saarbrücken: Novas Edições Acadêmicas, 2016.

MARQUES, A.B., 2002. Biologia reprodutiva do bagre Genidens genidens (Valenciennes, 1839) na Barrra da Lagoa do Açu, Norte do Estado do Rio de Janeiro, RJ. Dissertação (Mestrado) - Universidade Estadual do Norte Fluminense - UENF - Campos dos Goytacazes, RJ, 86p

SILVA, Juliana Ribeiro da; SILVA, Míriam Belarmindoda; VAREJÃO, José Leonídio. Os (dês)caminhos da educação: a importância do trabalho de campo na geografia. Revista VÉRTICES, Campos dos Goytacazes/RJ, v. 12, n. 3, p. 187-197, set./dez. 2010.

SOFFIATI NETTO, A.A. Ecofisionomia e História. In: SUZUKI, M.S. et al. Áreas Alagáveis do Norte Fluminense, 2005.

SUGUIO, K. Geologia sedimentar. São Paulo: Edgard Blucher, 2003. 400 p.

TRINDADE, M. Lagos: Origem, Classificação e Distribuição Geográfica. Departamento de Ciências Biológicas. São Carlos, Universidade Federal de São Carlos, 1996. 274 p. 